neonates undergoing palliative surgery $(\mathrm{p}=0.0003)$ and complete repair $(\mathrm{p}=0.000001)$.

\section{PO-0025 WITHDRAWN}

\section{PO-0026 ECHOCARDIOGRAPHIC ASSESSMENT OF CORONARY ARTERIES USING HIGH RESOLUTION TRANSTHORACIC ECHOCARDIOGRAPHY IN PATIENTS WITH A PREVIOUS DIAGNOSIS OF KAWASAKI DISEASE}

${ }^{1} \mathrm{~V}$ Giacchi, ${ }^{2} \mathrm{P}$ Sciacca, ${ }^{1} \mathrm{~S}$ Stella, ${ }^{1} \mathrm{M}$ Filippelli, ${ }^{1} \mathrm{P}$ Barone, ${ }^{1} \mathrm{M}$ La Rosa, 'S Leonardi. ${ }^{1}$ Pediatric Department, AOU Policlinico-Vittorio Emanuele, Catania, Italy; ${ }^{2}$ Pediatric Cardiology Clinic, AOU Policlinico-Vittorio Emanuele, Catania, Italy

\subsection{6/archdischild-2014-307384.704}

Background and aim Kawasaki disease (KD) is a generalised systemic vasculitis of unknown aetiology involving medium and small size blood vessels, particularly the coronary arteries, in which a progressive stenosis may result from active remodelling with an intimal proliferation and neoangiogenesis. The aim of our study was to assess if subjects with a previous diagnosis of KD show, after several years, a coronary intimal thickening, suggestive of a persistent cardiovascular risk, by using high-resolution transthoracic echocardiography (HRTE).

Methods We conducted an observational cross-sectional case-control double-blind study on 21 patients with a previous diagnosis of $\mathrm{KD}$ who had been hospitalised, as children, since January 1990 to December 1999 in our Paediatric Department of the University of Catania, Italy. We performed colordopplerechocardiography in all patients assessing measurement of thickening, inner diameter and outer diameter of proximal portion of left coronary artery using HRTE.

The cardiologic data were compared with those of the 21 healthy subjects of the same age.

Results We found a significant intimal thickening in patients with previous $\mathrm{KD}$ compared to healthy controls $(3.9 \mathrm{~mm} \pm 2.4$ $\mathrm{mm}$ vs $1.8 \mathrm{~mm} \pm 0.6 \mathrm{~mm} \mathrm{p}<0.05)$. In particular, we noticed that also subjects not suffering from coronary impairment in acute phase have higher values of thickening than healthy controls, configuring a higher cardiovascular risk.

Conclusions We concluded that the assessment of coronary artery thickening by means of HRTE may become an essential instrument to evaluate late cardiovascular risk in subjects with a diagnosis of KD in childhood.

\section{PO-0027 INTERSTITIAL FLUID COLLOID OSMOTIC PRESSURE IN HEALTHY CHILDREN}

${ }^{1} \mathrm{HJ}$ Guthe, ${ }^{2} \mathrm{M}$ Indrebø, ${ }^{3} \mathrm{~T}$ Nedrebø, ${ }^{4} \mathrm{G}$ Norgård, ${ }^{3} \mathrm{HJ}$ Wiig, ${ }^{1} \mathrm{~A}$ Berg. ${ }^{1}$ Department of Paediatrics, University of Bergen, Bergen, Norway; ${ }^{2}$ Department of Clinical Medicine Faculty of Medicine, University of Oslo, Oslo, Norway; ${ }^{3}$ Department of Biomedicine, University of Bergen, Bergen, Norway; ${ }^{4}$ Department of Clinical Medicine Faculty of Medicine Section for Paediatric Heart- Lung- and Allergic Diseases, University of Oslo, Oslo, Norway

\subsection{6/archdischild-2014-307384.705}

Background and aims Colloid osmotic pressure (COP) of plasma and interstitial fluid play important roles in transvascular fluid exchange were small pressure alterations may result in fluid shifts into or out of the capillaries optimising homeostasis. This

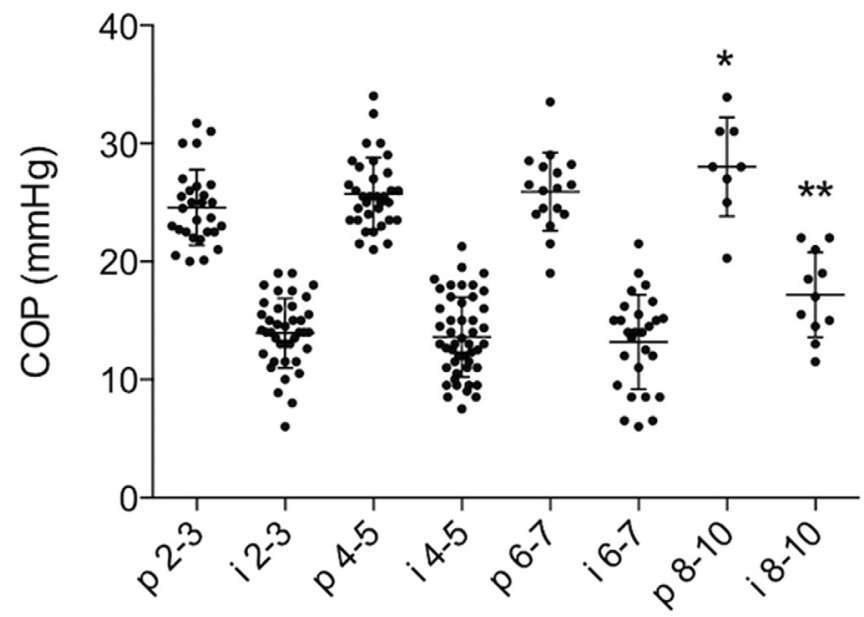

Abstract P0-0027 Figure 1 Colloid osmotic pressure in plasma and interstitium. Colloid osmotic pressure in plasma (p) and interstitium (i) (arm and leg merged) related to age. There was significant difference in pressure beween $2-3$ years and $8-10$ years for plasma $(p<0.05$, *) and between first three age groups and $8-10$ years $\left(p<0.01,{ }^{* *}\right)$ in interstitial fluid

study was conducted to determine reference values of COP in healthy children, and to evaluate the methodology of harvesting interstitial fluid.

Methods COP in plasma and interstitial fluid isolated from nylon wicks implanted subcutaneously was measured in 99 healthy children from 2 to 10 years of age. Patients were sedated and intubated during wick implantation in arm and leg, and COP was analysed in a colloid osmometer.

Results Mean plasma COP in all children was $25.6 \pm 3.3$ $\mathrm{mmHg}$. Arbitrary division of children in age groups, showed no significant difference in plasma or interstitial fluid COP values for patients less than 8 years, whereas patients of $8-10$ years had significant higher COP both in plasma and interstitial fluid. There was no gender difference or correlation between COP in interstitial fluid sampled from arm and leg and no significant effect on interstitial COP of gravity. Prolonged implantation time did not affect interstitial COP.

Conclusions This study justifies the presumption that plasma and interstitial COP in healthy children are similar to adults.

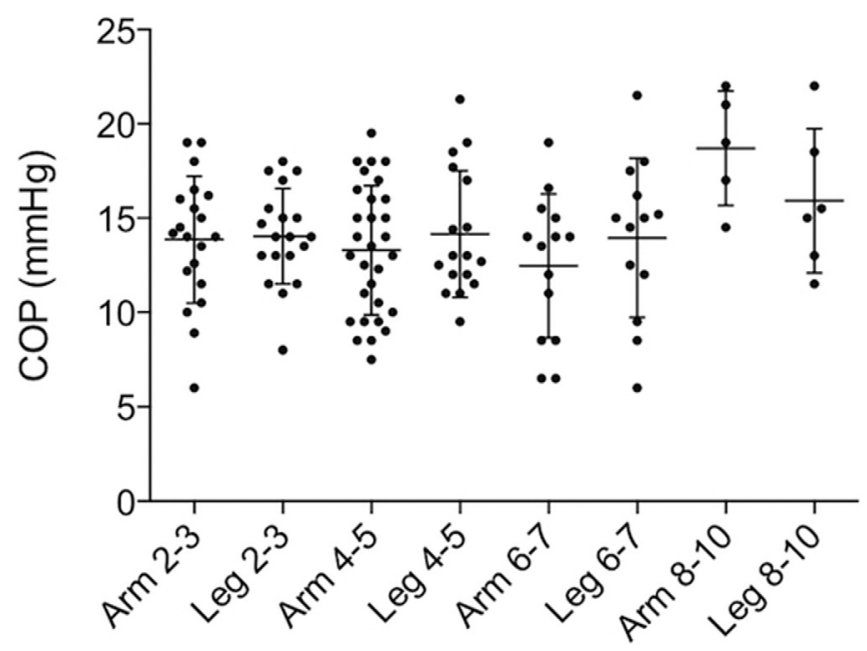

Abstract P0-0027 Figure 2 Colloid osmotic pressure in arm and leg. Colloid osmotic pressure from wicks after implantation in arm vs. leg related to age. There was no significant difference in the pressures obtained in arm and leg 
Children between 8 and 10 years had higher values than younger age groups. Knowledge of interaction between colloid osmotic forces in health and disease can be helpful in diseases associated with fluid imbalance and may be crucial in deciding different fluid treatment options.

\section{PO-0028 MARKERS OF THE EARLY EXTUBATION AFTER PAEDIATRIC CARDIAC SURGERY}

M Halimic, S Dinarevic, Z Begic, A Kadic. Cardiology Department, Paediatric Clinic Clinical Centre University of Sarajevo, Sarajevo, Bosnia and Herzegovina

10.1136/archdischild-2014-307384.706

Introduction Despite recent advances in anaesthesia, cardiopulmonary bypass and surgical techniques, children undergoing congenital heart surgery require postoperative mechanical ventilation. Early extubation was defined as ventilation shorter than $12 \mathrm{~h}$.

Aim To identify markers associated with successful early extubation after paediatric cardiac surgery.

Methods Retrospective-prospective clinical study was performed in Paediatric Clinic and Heart Centre Clinical Centre Univerity of Sarajevo during period from 01.01.2006. till 01.01.2011. Study included 100 children up to 5 years of age with congenital heart disease with left-right shunt and opstructive congenital heart disease, Patients were devided into two groups: I Group54 patients extubated within $12 \mathrm{~h}$ after surgery and Group II46 patients extubated more then $12 \mathrm{~h}$ after surgery.

Results The most frequently encountered preopeartive variables were age with odds ratio 4\% 95\% CI(1-7\%), Down's syndrome $8,595 \%$ CI $(1,6-43,15)$, failure to thrive 4,3 95\% CI(1-18). Statisticly significant postoperative data included lung disease (reactive airways, pneumonia, atelectasis, pneumothorax) and with odds ratio 35,1 95\% CI (4-286) and blood transfusion with odds ratio 4,6 95\% CI(2-12). Proven markers were age with cut of 21,5 months (sensitivity $74 \%$ and specificity $70 \%$ ) and extracorporeal circulation (ECC) with cut of 45,5 min (sensitivity $71 \%$ and specificity $65 \%$ ).

Conclusion Younger age and prolonged time ECC are markers associated with prolonged mechanical ventilation.

\section{PO-0029 WITHDRAWN}

\section{PO-0030 CASE REPORT: HEPARIN-INDUCED THROMBOCYTOPENIA (HIT) IN TWO CHILDREN AFTER FONTAN PROCEDURE}

A Hofer, M Heschl. Anesthesiology and Intensive Care, Gerneral Hospital Linz, Linz, Austria

10.1136/archdischild-2014-307384.707

Background and aims Incidence of HIT in childhood is lower than in adults because of lower platelet factor 4 levels and immature immune system. After frist time cardiac surgery platelet-antibody formation has been reported to be $1,7 \%$ in neonates and $6 \%$ in children on the 5 th postoperative day. With reexposure to unfractionated heparin (UFH) even $52 \%$ of children are antibody positive but only $1.3 \%$ develope symptoms. ${ }^{1}$

Methods and results Two children ( 3 and 3.5 years old) developed thrombopenia after Fontan procedure (after 5 and 7 days

\begin{tabular}{lllllll}
\multicolumn{2}{l}{ Abstract PO-0030 Table 1 } \\
$\begin{array}{llllll}\text { Argatroban } \\
\text { Date }\end{array}$ & Time & $\begin{array}{l}\text { aPTT } \\
\text { Thg/kg/min }\end{array}$ & $\begin{array}{l}\text { G/l } \\
299\end{array}$ & INR & $\begin{array}{l}\text { Marcoumar } \\
\mathbf{m g}\end{array}$ \\
8.11 .12 & $7: 47$ & 35 & 1 & 58 & & \\
26.11 .12 & $7: 00$ & 70 & 4,13 & 528 & 2,67 & 2 \\
28.11 .12 & $10: 00$ & 88 & 4,13 & & 2,4 & 2 \\
29.11 .12 & $11: 00$ & $>240$ & Pause & & 6,56 & 2 \\
29.11 .12 & $12: 00$ & 94 & Pause & & & - \\
29.11 .12 & $20: 50$ & 106 & 2,36 & & & - \\
30.11 .12 & $3: 12$ & 99 & ex & & 3,9 & 1.5 \\
2.12 .12 & $8: 00$ & & & & 4,4 & 1
\end{tabular}

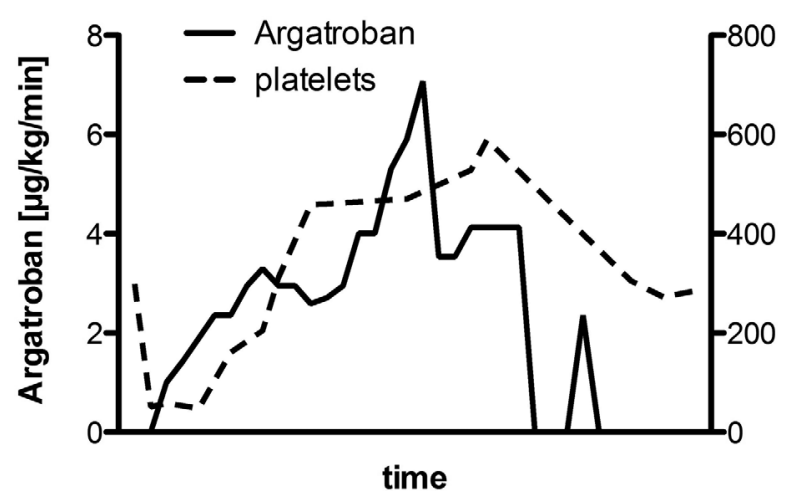

Abstract PO-0030 Figure 1

respectively). One patient suffered from cyanosis due to a thrombus in the Fontan tunnel. Both were initially treated with with continuous argatroban infusion and then switched to a vitamin $\mathrm{k}$ antagonist. In the second patient aPTT and INR exceeded therapeutic values during transition, because argatroban dosage was not reduced adequately. (Table 1)

Conclusion In both patients platelet count recoverd. No adverse events, especially no argatroban induced bleeding occured. aPTT and INR should be monitored closely and dosage should be adapted accordingly.

1 Mullen et al. Anesth Analg. 2008; 107(2):371-378

2 Niyati et al. Pediatric Pharmacol Ther. 2012; 17(1):12-30

\section{PO-0031 PREFERABLE DISORDERS IN THE CHILDREN WITH PRIMARY ARTERIAL HYPERTENSION ASSOTIATED WITH ENDOTHELIAL DISFUNCTION}

${ }^{1} \mathrm{OM}$ Horlenko, ${ }^{2} \mathrm{VI}$ Rusyn, ${ }^{1} \mathrm{NV}$ Sochka, ${ }^{2} \mathrm{OO}$ Boldizhar, ${ }^{1} \mathrm{OV}$ Debreceni, ${ }^{2} \mathrm{FV}$ Horlenko. ${ }^{1}$ Pediatric with Infectious Diseases, Uzhgorod National University Medical Faculty, Uzhgorod, Ukraine; ${ }^{2}$ Surgical Diseases, Uzhgorod National University Medical Faculty, Uzhgorod, Ukraine

\subsection{6/archdischild-2014-307384.708}

Background and aims Endothelial dysfunction (DE)-a state of the vascular endothelium, which is accompanied by vazotonic, remodelic, anti-inflammatory and anticoagulant functions. The range of these disorders, the severity of each, and chronology of occurrence, the dynamic progression vary depending on the nosology pathology.

Methods The investigated group included of 36 children (age $13,98 \pm 0,16)$ with diagnosed primary arterial hypertension assotiated with DE. The scientific study was conducted in the Transcarpathian region of Ukraine. 